\title{
BMJ Open Quality Increasing contraception use among women receiving teratogenic medications in a rheumatology clinic
}

\author{
Rebecca E Sadun, ${ }^{1}$ Melissa A Wells, ${ }^{2}$ Stephen J Balevic, ${ }^{1}$ Victoria Lackey, ${ }^{3}$ \\ Erica J Aldridge, ${ }^{4}$ Nicholas Holdgagte, ${ }^{5}$ Samya Mohammad, ${ }^{6}$ \\ Lisa G Criscione-Schreiber, ${ }^{1}$ Megan E B Clowse, ${ }^{1}$ Mamata Yanamadala ${ }^{7}$
}

To cite: Sadun RE, Wells MA, Balevic SJ, et al. Increasing contraception use among women receiving teratogenic medications in a rheumatology clinic.BMJ Open Quality 2018;7:e000269. doi:10.1136/ bmjoq-2017-000269

Received 27 November 2017 Revised 3 June 2018 Accepted 9 June 2018

\section{Check for updates}

(c) Author(s) (or their employer(s)) 2018. Re-use permitted under CC BY-NC. No commercial re-use. See rights and permissions. Published by BMJ.

${ }^{1}$ Division of Rheumatology, Department of Medicine, Duke Health, Durham, North Carolina, USA

${ }^{2}$ Colorado Center for Arthritis and Osteoporosis, Boulder, Colorado, USA

${ }^{3}$ Arthritis and Osteoporosis Consultants of the Carolinas, Charlotte, North Carolina, USA

${ }^{4}$ Baptist Medical Group Rheumatology, Pensacola, Florida, USA

${ }^{5}$ Lowcountry Rheumatology, Charleston, South Carolina, USA ${ }^{6}$ Emerge0rtho, Durham, North Carolina, USA

${ }^{7}$ Division of Geriatrics,

Department of Medicine, Duke Health, Durham, North Carolina, USA

Correspondence to Dr Rebecca E Sadun; rebecca.sadun@duke.edu

\section{ABSTRACT}

Teratogenic medications are often prescribed to women of childbearing age with autoimmune diseases. Literature suggests that appropriate use of contraception among these women is low, potentially resulting in high-risk unintended pregnancies. Preliminary review in our clinic showed suboptimal documentation of women's contraceptive use. We therefore designed a quality improvement initiative to target three process measures: documentation of contraception usage and type, contraception counselling and provider action after counselling. We reviewed charts of rheumatology clinic female patients aged 18-45 over the course of 10 months; for those who were on teratogenic medications (methotrexate, leflunomide, mycophenolate and cyclophosphamide), we looked for evidence of documentation of contraception use. We executed multiple plan-do-study-act (PDSA) cycles to develop and evaluate interventions, which centred on interprofessional provider education, modification of electronic medical record (EMR) templates, periodic provider reminders, patient screening questionnaires and frequent feedback to providers on performance. Among eligible patients $(n=181)$, the baseline rate of documentation of contraception type was $46 \%$, the rate of counselling was $30 \%$ and interventions after counselling occurred in $33 \%$ of cases. Averaged intervention data demonstrated increased provider performance in all three domains: documentation of contraception type increased to $64 \%$, counselling to $45 \%$ and provider action to $46 \%$. Of the patients with documented contraceptives, $50 \%$ used highly effective, $27 \%$ used effective and $23 \%$ used ineffective contraception methods. During this project, one unintentional pregnancy occurred in a patient on methotrexate not on contraception. Our interventions improved three measures related to contraception counselling and documentation, but there remains a need for ongoing quality improvement efforts in our clinic. This high-risk population requires increased provider engagement to improve contraception compliance, coupled with system-wide EMR changes to increase sustainability.

\section{PROBLEM}

Given that teratogenic medications prescribed to women with rheumatic diseases may cause significant fetal harm, contraception counselling is a critical component of safely prescribing such medications. Prior to initiation of the project, we discovered that use of contraception was documented in only $46 \%$ of encounters for females at risk of becoming pregnant while taking teratogenic medications. Given the low documentation performance rate, we designed a quality improvement (QI) initiative with the aim of improving, by $20 \%$ over 10 months, documented contraception and counselling in women of childbearing age who are receiving teratogenic medications in the rheumatology clinic.

This was a fellow-led QI initiative conducted over a 10-month period, during the 20152016 academic year, in the Duke University Rheumatology Clinic, which is an academic outpatient rheumatology setting. Duke Health is a tertiary care centre located in the Southeastern USA; our outpatient consultative practice conducts approximately 12000 visits per year, constituting a wide variety of diagnoses. Just under two-thirds of patients in this clinic describe themselves as Caucasian with another quarter describing themselves as Black or African-American; $78 \%$ of the encounters seen each year are for female patients. Clinic providers include faculty rheumatologists, rheumatology fellows and nurse practitioners. Patients are seen in the rheumatology clinic for a variety of rheumatic diseases, including systemic lupus erythematosus (SLE), rheumatoid arthritis (RA), inflammatory myopathies, systemic sclerosis, mixed connective tissue disease and other autoimmune and musculoskeletal conditions.

\section{BACKGROUND}

It is estimated that $5.8 \%$ of all pregnancies in the USA are exposed to category D or $\mathrm{X}$ medications, although the specific rate for rheumatology patients is unknown. ${ }^{1}$ An estimated half of all pregnancies in are 
unplanned, meaning that many women are at risk for pregnancy even when they are not trying to conceive. Unfortunately, women with SLE and RA have been shown to be less likely to use contraception compared with healthy controls. ${ }^{23}$ Furthermore, rheumatology patients reporting contraception use have been found to practice methods with a high failure rate, such as natural family planning or barrier methods alone. ${ }^{23}$ Inadequate or ineffective contraception places women who are on teratogenic medications at higher risk for both pregnancy loss and offspring with birth defects.

Given the risk for fetal harm, experts have identified contraception counselling as crucial to the management of patients receiving teratogenic medications. ${ }^{45}$ Gillis et al published the quality indicator statement related to the care of patients with SLE: 'IF a woman between 18 and 45 years of age is started on a medication for SLE (eg, methotrexate (MTX), mycophenolate mofetil (MMF), leflunomide (LEF) or cyclophosphamide (CYC)), THEN a discussion with the patient about the potential teratogenic risks of therapy and about contraception should be documented prior to drug initiation, unless the patient is unable to conceive (eg, hysterectomy, oophorectomy, tubal ligation or postmenopausal), BECAUSE these drugs either have teratogenic potential or pose an unknown risk to the developing fetus' ${ }^{6}$ A similar quality measure statement was published by the Arthritis Foundation in 2004 for women with RA. ${ }^{5}$ Studies in patients with SLE reveal that one-third to one-half of patients do not report or do not have documented discussions regarding potential pregnancy risks with initiation of teratogenic medications. ${ }^{78}$ Lack of adherence to suggested quality measures places our patients at increased risk of harm, but also presents an opportunity for QI.

\section{BASELINE MEASUREMENT}

We reviewed clinic charts to ascertain three primary measures of interest: contraception use, contraception counselling and provider action after counselling. Data were collected for a total of 10 time points over a 10-month period. Inclusion criteria for chart review for encounters were: females between the ages of 18 and 45 with a documented prescription for MTX, LEF, CYC or MMF. The medication and ages selected were based on published quality indicator statements. ${ }^{6}$ We used the following operational definitions:

- At risk for pregnancy: women of childbearing age who did not have prior tubal ligation or hysterectomy.

- Contraception use: a type of contraception listed in one or more of the following locations: medication list, social history, review of systems (ROS), provider assessment or medical/surgical history.

- Contraception counselling: a statement in the provider note regarding discussion of contraception.

- Provider action (after counselling): documentation of further action taken, placement of a referral to gynaecology or the prescription of contraception.
For encounters in which the patient met inclusion criteria, we collected the following information: (1) patient age (years), (2) type of teratogenic medication, (3) documented contraception use (yes/no), (4) type of contraception, (5) documented contraception counselling during the visit (yes/no) and (6) further provider action taken (yes/no). Only rheumatology clinic notes during each sampling week were included; other EMR documentation was not reviewed.

A total of 3003 patient encounters were screened, identifying 181 eligible patients, whose charts were reviewed in detail. Median age at time of study was 35 years (range: 19-45). MTX was the most commonly used teratogenic medication, taken by 88 patients $(49 \%)$, followed by MMF with 71 patients (41\%), LEF with 11 patients $(6 \%)$, CYC with five patients $(3 \%)$ and three patients $(2 \%)$ were prescribed combination therapy. Among eligible patients $(n=181)$, the baseline rate of documented contraception use was $46 \%$, the rate of counselling was $30 \%$ and provider action after counselling occurred in $33 \%$ of cases. Any changes in the selected measures were attributed to the interventions.

\section{DESIGN}

The project team included a total of six rheumatology fellows, supplemented with expert advice from three faculty rheumatologists and one non-rheumatology faculty member. We applied for and received exemption from our institution's IRB (research ethics committee) on the basis of qualifying as a low-risk QI study. Fellows collaborated formally on a weekly basis and communicated informally daily. We executed multiple plan-dostudy-act (PDSA) cycles to develop and evaluate interventions to increase documentation of contraception use, contraception counselling and provider action. 9

Interventions included: three separate QI project presentations at divisional conferences, the addition of a contraception question to the review of systems (ROS) in willing providers' EMR note templates (figure 1A), screening questionnaires for patients to complete during their clinic check-in process (figure 1B) and meetings with clinical staff and faculty. The interventions were selected during stakeholder discussions with faculty and staff and based on the desire to build and maintain 'buy in', as well as the desire to create a sustainable, systemsbased change within the EMR. We believed a multifaceted approach would allow for several 'checkpoints' to trigger the QI intervention during routine clinic visits.

Information regarding contraception type was analysed in aggregate over the intervention period. Contraception type was categorised based on typical use effectiveness for pregnancy prevention as follows: A contraceptive method was considered 'highly effective' if the estimated 1 year effectiveness was greater than 95\% (examples: intrauterine device or implant) based on estimates for typical use, 'effective' if the estimated 1 year effectiveness was $90 \%-94 \%$ (examples: oral contraceptive pills or 
A Review of Systems Template Language

The patient is prescribed a high risk medication that carries potential for birth defects or miscarriage. These risks were discussed with the patient as well as the importance of appropriate contraception use. The patient has elected to: Drop Down Menu - Select one of the following:

seek gynecology referral to select contraception

use condoms and Depo-provera

use condoms and OCPs

use an implantable device

use tubal ligation

remain abstinent

or partner vasectomy

...to prevent unplanned pregnancy.

B Patient Screening Questionnaire

Instructions: Please check the boxes that apply:

1. Are you a woman between the ages of 18 and 45 ?

$\square$ Yes $\square$ No (no further action is required - you can stop here)

2. Have you had a tubal ligation or do you currently have an IUD?

$\square$ No $\square$ Yes (no further action is required - you can stop here)

3. Are you taking one or more of the following medications (if so, please check the corresponding box):

$\square$ Methotrexate (Rheumatrex, Trexal, Otrexup)

$\square$ Mycophenolate (CellCept or Myfortic)

Leflunomide (Arava)

Cyclophosphamide (Cytoxan) either as a pill or through infusion

** Becoming pregnant while taking one of these medications can cause severe birth defects. It is important to prevent pregnancy while taking these medications. **

4. Are you currently using birth control?

$\square$ Yes-please indicate which form below $\quad \square$ No-please discuss this with your provider

5. If yes, which method of birth control are you using (check all that apply):

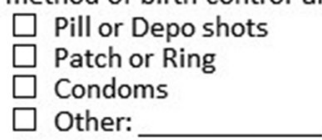

Please give this form to your doctor and discuss whether your contraceptive method is adequate to prevent pregnancy.

Figure 1 Tools developed for interventions. (A) review of systems dot phrase placed in electronic medical record note templates to prompt providers to ask about patients' contraception use and (B) screening questionnaire given to patients during check-in to enable patients to self-identify the need to discuss contraception with their provider.

patch), and 'ineffective' if the estimated effectiveness was less than $90 \%$ (examples: condom only use). ${ }^{10}$ We used run charts to display and assess the three contraception process measures: type, counselling and provider action. To determine overall improvement between baseline and intervention for these three measurements, baseline data from August was compared with averaged data from all postintervention time points (September 2014 to May 2015). Participants with multiple visits throughout the intervention period were analysed according to their visit data. Descriptive statistics were used to summarise this data.

\section{STRATEGY}

\section{PDSA cycle 1: rheumatology divisional conference}

\section{discussion}

We sought to increase stakeholder support for the project by including them in the decision regarding which QI project to undertake. We introduced three potential QI projects and asked faculty to vote anonymously on their preferred project. The majority of faculty selected this contraception documentation project. Following this initial presentation and selection process, documentation of patients with contraception type, contraception counselling and provider action remained unchanged. Discussion with clinicians highlighted difficulty remembering to discuss contraception as the major barrier to performance. This cycle enabled us to select a QI project and identify the barrier of lapse in provider memory, which we targeted in our next intervention.

\section{PDSA cycle 2: ROS question}

The aim of this cycle was to improve memory by adding a cue within the EMR. We therefore added a question to the ROS section in providers' EMR note templates. We approached 19 providers and received permission to add the intervention ROS question to each of their templates. At the end of this intervention period, documentation of contraception use had risen from $46 \%$ to $75 \%$, contraception counselling from $30 \%$ to $44 \%$ and provider action from $33 \%$ to $50 \%$. This cycle enabled us to identify a significant barrier to our intervention: note cloning, meaning 
bringing forward and editing the note from the last clinic visit. As the prior note wouold not have included the contraception prompt, note cloning impeded utilisation of the new ROS prompt by some providers.

\section{PDSA cycle 3: second divisional conference discussion}

The aim of this cycle was to provide a project update, identify barriers and discuss with stakeholders how to help providers incorporate contraception counselling into their patient visit routine. We presented an update on the status of the QI project at our divisional conference, including aggregate data for the rates of documentation. Following the presentation, documentation of contraception type and contraception counselling reached $64 \%$ and $46 \%$, respectively; provider action was $33 \%$. Discussion with stakeholders during this cycle highlighted the challenge of identifying patients who required documentation of contraception type and counselling.

\section{PDSA cycle 4: physician reminder system using patient screening questionnaires}

The aim of this cycle was to help patients self-identify as in need of contraception. We developed a paper screening questionnaire and created a process to distribute them to patients during clinic check-in. The questionnaire asked patients whether they were taking any of the teratogenic medications and whether they were using contraception. Nursing staff collected completed questionnaires from patients and placed them with the usual intake form given to providers when a patient was ready to be seen. After initiation of the paper surveys, documentation of contraception use was $59 \%$, contraception counselling was $54 \%$ and provider action was $57 \%$. This cycle enabled us to assess the effects of including patients as stakeholders.

\section{PDSA cycle 5: third divisional conference discussion}

The aim of this cycle was to update faculty and staff on project progress. We gave a third divisional conference presentation and discussed the status of the project, aggregate documentation rates and the patient screening questionnaire. After this presentation, contraception documentation rose to $67 \%$ and contraception counselling to $64 \%$, while provider action became $43 \%$. At this session, providers indicated that they did not understand the purpose of the screening questionnaires and described confusion taking place during the patient check-in process, including the patient screening questionnaire being given to male patients and others not at risk for impregnation. This cycle enabled us to plan corrective action regarding the patient intervention by planning two additional meetings/interventions, one with faculty and one with clinic staff.

\section{PDSA cycle 6: faculty meeting discussion}

The aim of this cycle was to address clinical faculty concerns regarding the patient screening questionnaire. A fellow attended a clinical faculty meeting to review the intervention and address specific provider questions. Documentation of contraception use was then measured at $58 \%$, contraception counselling at $38 \%$ and provider action at $67 \%$.

\section{PDSA cycle 7: clinic staff meeting}

The aim of this cycle was to improve implementation of the patient screening questionnaire. A fellow attended a clinic staff meeting to discuss the purpose of the patient screening questionnaires with nursing staff and to clarify intended workflow. Documentation of contraception use following this intervention was $62 \%$, contraception counselling was $33 \%$ and provider action was $63 \%$. This was the final cycle and demonstrated the importance of considering the impact of workflow at all stages of the intervention (front desk to patient to nursing to provider).

\section{RESULTS}

Table 1 outlines the interventions and outcomes. Taken in aggregate, overall documentation of contraception increased from $46 \%$ to $64 \%$, contraception counselling increased from $30 \%$ to $45 \%$ and provider action increased from $33 \%$ to $46 \%$. The majority of patients had a type of contraception documented $(\mathrm{n}=114 / 181,63 \%)$ while 67 patients $(37 \%)$ did not have any contraception type documented (see figure 2). Of the 114 patients with documented contraception type, 57 (50\%) were using 'highly effective' contraception, 31 (27\%) patients reported use of 'effective' contraception and 26 (23\%) patients were using 'ineffective contraception'. Because documentation was both a measurement outcome and the primary data, there were no missing data (ie, missing data was imputed as no documentation).

PDSA interventions and rates of change in our three measurements are documented in the run chart (see figure 3). The most significant improvements in documentation occurred after the first cycle, when stakeholder enthusiasm was highest, and after the last cycle, having optimised use of the patient screening questionnaire. The most significant improvement in counselling occurred after cycle 4, when patient screening questionnaires were first introduced. Provider action gradually increased throughout the interventions, with the largest increases occurring after the two conference presentations (cycles 3 and 5).

During the course of the review, we discovered one patient had experienced an unintentional pregnancy while taking MTX; this pregnancy ended in miscarriage.

\section{Lessons and limitations}

In this QI project, we increased documentation of contraception type from $46 \%$ to $64 \%$, rate of contraception counselling from $30 \%$ to $45 \%$ and provider action from $33 \%$ to $46 \%$. Of those patients with documented type of contraception, the majority were using either effective or highly effective methods of contraception. Unfortunately, 67 patients did not have any type of contraception documented and 26 patients were using ineffective contraception (either abstinence or condoms only). 
Table 1 Plan-do-study-act (PDSA) interventions and results.

\begin{tabular}{|c|c|c|c|c|}
\hline & Time implemented & Description & Result: number/total (\%) & Observations \\
\hline Baseline & August & $\begin{array}{l}\text { Performance prior to } \\
\text { interventions }\end{array}$ & $\begin{array}{l}\text { Documentation: } 6 / 13(46 \%) \\
\text { Counselling: } 3 / 10(30 \%) \\
\text { Provider action: } 1 / 3(33 \%)\end{array}$ & - Not applicable \\
\hline PDSA \#1 & September & $\begin{array}{l}\text { Rheumatology conference for } \\
\text { stakeholders }\end{array}$ & $\begin{array}{l}\text { Documentation: } 7 / 15(47 \%) \\
\text { Counselling: } 6 / 12(50 \%) \\
\text { Provider action: } 2 / 6(33 \%)\end{array}$ & $\begin{array}{l}\text { Provider difficulty } \\
\text { remembering to } \\
\text { discuss }\end{array}$ \\
\hline PDSA \#3 & November & $\begin{array}{l}\text { Rheumatology conference for } \\
\text { stakeholders and discuss of ROS }\end{array}$ & $\begin{array}{l}\text { Documentation: } 9 / 14(64 \%) \\
\text { Counselling: } 6 / 13(46 \%) \\
\text { Provider action: } 2 / 6(33 \%)\end{array}$ & $\begin{array}{l}\text { Education did not } \\
\text { produce sustained } \\
\text { effects }\end{array}$ \\
\hline PDSA \#5 & Mid-April & $\begin{array}{l}\text { Rheumatology conference } \\
\text { presentation to discuss } \\
\text { questionnaires }\end{array}$ & $\begin{array}{l}\text { Documentation: 8/12 (67\%) } \\
\text { Counselling: } 7 / 11(64 \%) \\
\text { Provider action: } 3 / 7(43 \%)\end{array}$ & $\begin{array}{l}\text { Desire for } \\
\text { standardised method } \\
\text { of notification }\end{array}$ \\
\hline PDSA \#6 & End-April & $\begin{array}{l}\text { Discussed questionnaires at } \\
\text { faculty meeting }\end{array}$ & $\begin{array}{l}\text { Documentation: } 7 / 12(58 \%) \\
\text { Counselling: } 3 / 8(38 \%) \\
\text { Provider action: } 2 / 3(67 \%)\end{array}$ & $\begin{array}{l}\text { Limited by physician } \\
\text { enthusiasm }\end{array}$ \\
\hline PDSA \#7 & May 2015 & $\begin{array}{l}\text { Discussed questionnaires at clinic } \\
\text { staff meeting }\end{array}$ & $\begin{array}{l}\text { Documentation: } 21 / 34(62 \%) \\
\text { Counselling: } 8 / 24(33 \%) \\
\text { Provider action: } 5 / 8(63 \%)\end{array}$ & $\begin{array}{l}\text { Extra sheet created } \\
\text { confusion within clinic } \\
\text { work flow }\end{array}$ \\
\hline
\end{tabular}

Our results are consistent with prior studies of contraceptive practices of patients with rheumatic disease. Contraception use in patients with SLE has been estimated to be $59 \%$, compared with $77 \%$ in healthy controls. $^{2}$ Yazadany et al found that more than half of the patients with SLE at risk for pregnancy who were on teratogenic medications did not recall receiving contraceptive counselling. ${ }^{3}$ Another study in patients with rheumatoid arthritis prescribed LEF found that up to $32 \%$ of premenopausal women were not using any

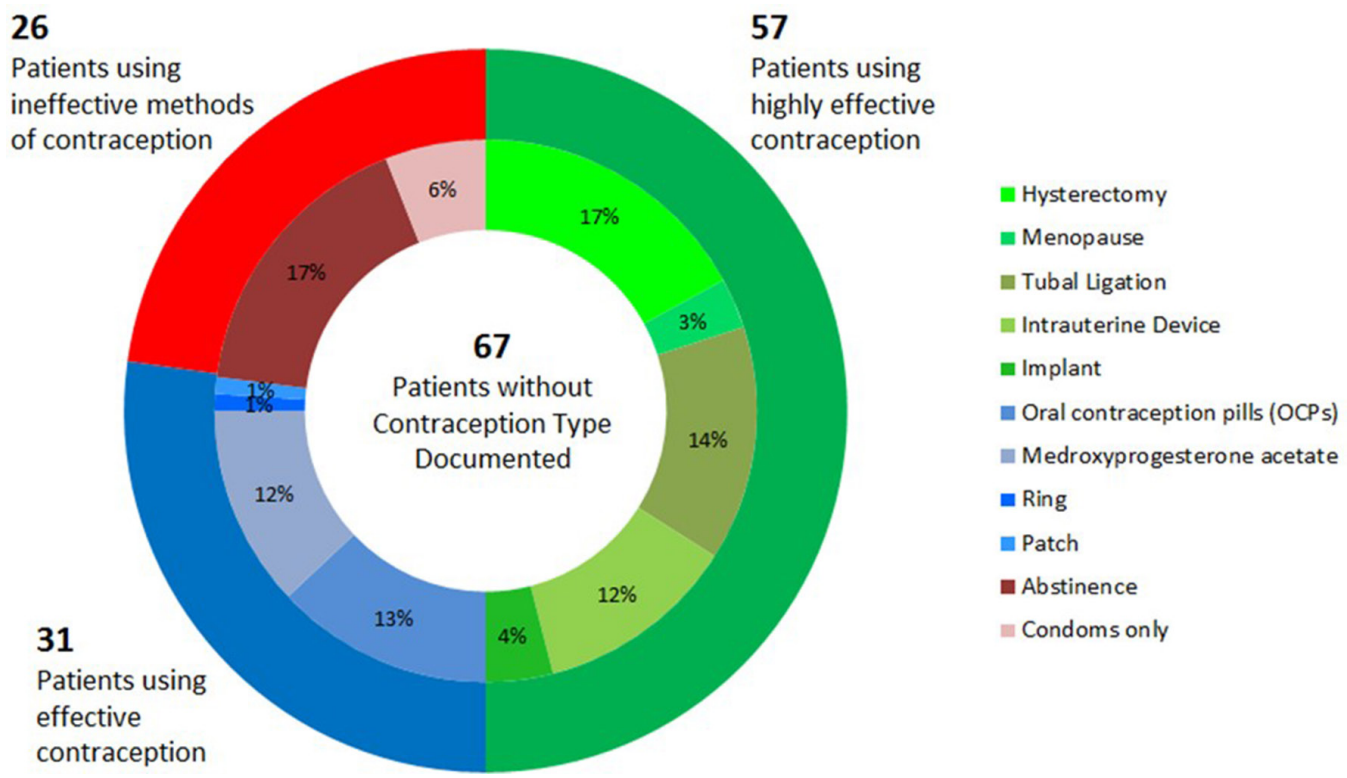

Figure 2 Types of contraception documented. Outer ring represents the total number of patients receiving highly effective contraception, effective contraception or ineffective contraception $(n=181)$. Inner ring describes percentage of patients by each contraception type $(n=114)$. 


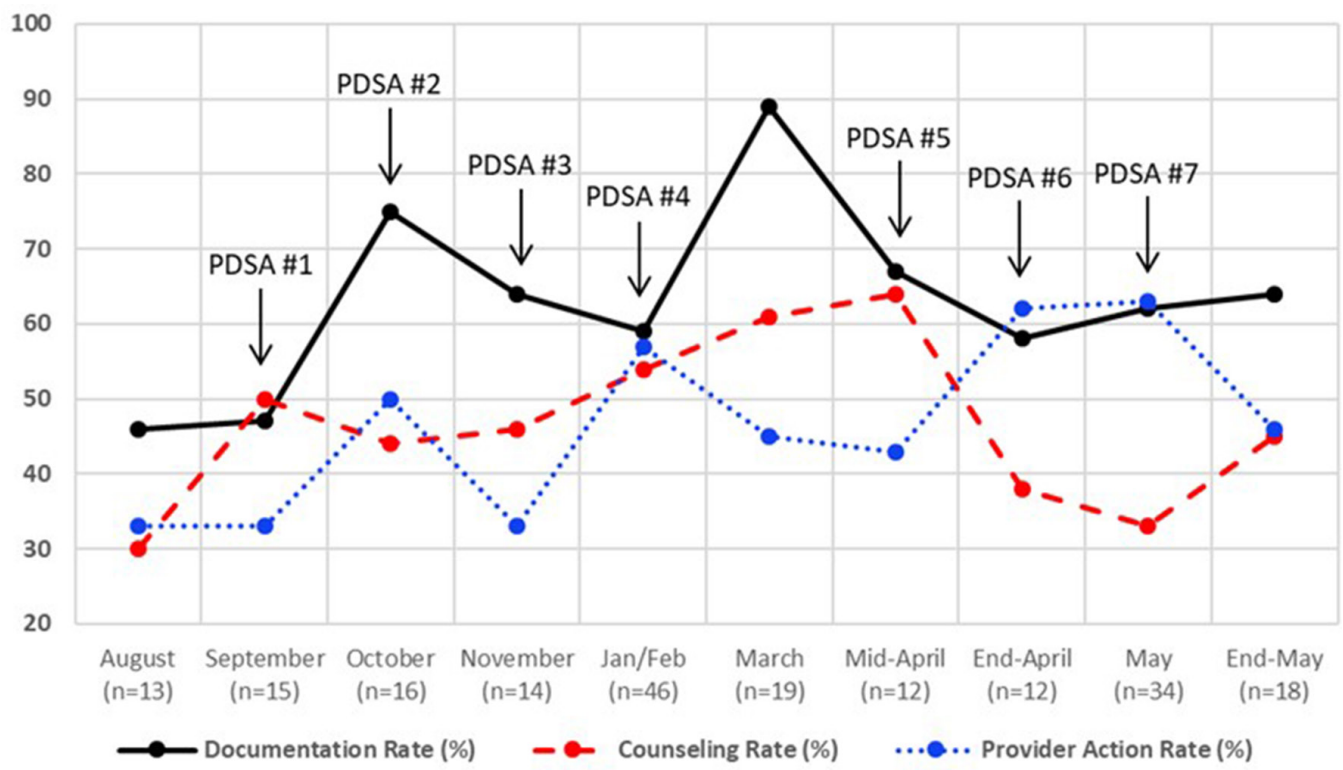

Figure 3 Run chart for plan-do-study-act (PDSA) cycles. Run chart for the three primary outcome measures throughout the 10 time points of the project. Timing of PDSA cycles are numbered and marked by arrows. PDSA \#1: rheumatology grand rounds presentation. PDSA \#2: addition of review of systems question. PDSA \#3: second rheumatology grand rounds presentation. PDSA \#4: paper reminder sheet system. PDSA \#5: third rheumatology grand rounds presentation. PDSA \#6: clinical faculty meeting discussion. PDSA \#7: clinical staff meeting discussion. Documentation rate=number of patients with contraception status identified over total number of eligible patients. In addition to the seven PDSA cycles, data was pulled and analysed at baseline (August), in March, and at the conclusion of the study (end-May). Counselling rate=number of patients who received conception counselling over total number of eligible patients. Provider action rate=number of patients who received further action was taken over the total number of patients who received counselling.

method of birth control. ${ }^{11}$ This same study found that patients were using ineffective contraceptive methods such as natural family planning in $32 \%$ of cases and condoms alone $16 \%$ of the time. Our study is the first to build on this literature by demonstrating the effectiveness of simple and inexpensive interventions to improve the rates of contraception documentation, counselling and provision.

Though contraception counselling has the potential to be controversial and some individuals have strong personal or religion-based preferences against the use of contraception, we did not encounter patients who expressed disapproval of this intervention. Contraception counselling remained objective, evidence-based and non-judgmental. Patients were counselled to avoid pregnancy while on teratogenic medications, but patients were never required to initiate contraception.

This QI initiative was able to achieve a significant and sustained increase in patient and provider engagement regarding initiating contraception for patients at risk for pregnancy while on a teratogenic medication. In addition, this fellow-driven project allowed team members to learn process improvement, a skill that can be applied in many settings and is a requirement of the Accreditation Council for Graduate Medical Education (ACGME) in the USA. ${ }^{12-14}$ An additional strength of this project relates to its simplicity and generalisability; any specialty can utilise the interventions developed in this initiative-the EMR template language and the patient questionnaire tools-to reduce pregnancy in women taking teratogenic medications.

The main limitation of this study, and others in the literature, is using physician contraception documentation as a surrogate for contraception use. There is a clear difference in reported contraception use and actual contraception use, as is highlighted by the large difference in 'perfect use' and 'actual use' efficacy of contraceptives. The focus of this QI project was physician behaviour, with the expectation that changes in physician behaviour could impact patient behaviour. Collecting patient-reported contraception use, and perhaps even objective evidence suggesting contraceptive use through prescription refills, would have been interesting, but out of the scope of this project. It is possible that the percentage of patients on contraception might be inaccurate due to the physician-focused methodology, but for a QI study, the accuracy of the baseline estimate is less meaningful than the percentage change over time.

The long duration of this initiative ( 10 months) may have led to some waning provider interest. The project required multiple interventions to achieve the goal of increasing documentation by at least $20 \%$ : despite straightforward interventions, developing buy-in throughout a group practice, involving all of the stakeholders and producing culture change is a gradual process.

A major barrier to implementation was the EMR practice of note cloning (ie, pulling forward previous notes). One of the most effective strategies employed was the 
introduction of a contraceptive reminder in the Review of Systems in note templates. The physicians who cloned notes, however, were not able to gain the benefit of this valuable approach. Others have also reported that the copy functionality of EMR can significantly impact information integrity within a patient's chart. ${ }^{12}{ }^{13} 14$ Future QI measures must target the practice of note cloning, although specific interventions depend on local EMR capabilities. Possible interventions could include: (1) mandatory hard stops created within notes that are pulled forward (or complete removal of the functionality) and (2) specific provider education to reduce note cloning.

While the objectives of this initiative were increasing contraception documentation, discussion and action, these are all process measures related to the over-arching goal of preventing unintentional pregnancies in women taking teratogenic medication. Our study identified one unplanned pregnancy in a woman taking MTX during the intervention period. No contraception type was documented in this woman's chart. While physician documentation and discussion is an important aspect of pregnancy prevention, patient understanding and buy-in is key. Future meaningful interventions could come from eliciting patient feedback regarding contraception use, with a focus on enhanced adherence.

Provider engagement in contraception for patients who take teratogenic medications continues to be a critical area for practice improvement. This QI project focused on a rheumatology practice, but providers in many specialties and subspecialties prescribe teratogenic medications, such as ACE-inhibitors in primary care. Thus, the outcomes of this study are thus highly generalisable. Improving documentation by providers is, of course, only one piece of the puzzle. Ultimately, a combination of interventions and involvement of all stakeholdersincluding patients-would most likely maximise quality performance. While $100 \%$ performance may never be attainable, we should aim to make unintended pregnancies on teratogenic medications a 'never event', and as such providers and practices must continue to strive to improve rates of contraception use.

\section{CONCLUSION}

In summary, the QI initiative described above improved care in our rheumatology clinic by increasing three process measures for contraception use among women taking teratogenic medications. Through several PDSA cycles, we were successful in improving contraception documentation, counselling and provider action. The interventions used are generalisable to most academic rheumatology practices with an EMR.
Ultimately, these and other interventions, including patient education, will be required to further improve these outcomes and prevent teratogen-exposed pregnancies. Future QI initiatives, regardless of practice type or patient population, can capitalise on our lessons learned by including patients as stakeholders early in the initiative.

Contributors RES, MAW, SJB and MY contributed to manuscript writing. All authors contributed to study planning, data collection and manuscript editing.

Funding The authors have not declared a specific grant for this research from any funding agency in the public, commercial or not-for-profit sectors.

Competing interests None declared.

Patient consent Not required.

Provenance and peer review Not commissioned; externally peer reviewed.

Open access This is an open access article distributed in accordance with the Creative Commons Attribution Non Commercial (CC BY-NC 4.0) license, which permits others to distribute, remix, adapt, build upon this work non-commercially, and license their derivative works on different terms, provided the original work is properly cited, appropriate credit is given, any changes made indicated, and the use is non-commercial. See: http://creativecommons.org/licenses/by-nc/4.0/.

\section{REFERENCES}

1. Eisenberg DL, Stika C, Desai A, et al. Providing contraception for women taking potentially teratogenic medications: a survey of internal medicine physicians' knowledge, attitudes and barriers. J Gen Intern Med 2010;25:291-7.

2. Julkunen HA, Kaaja R, Friman C. Contraceptive practice in women with systemic lupus erythematosus. Br J Rheumatol 1993;32:227-30.

3. Yazdany J, Trupin L, Kaiser R, et al. Contraceptive counseling and use among women with systemic lupus erythematosus: a gap in health care quality? Arthritis Care Res 2011;63:358-65.

4. Yazdany J, Panopalis P, Gillis JZ, et al. A quality indicator set for systemic lupus erythematosus. Arthritis Rheum 2009;61:370-7.

5. MacLean $\mathrm{CH}$, Saag KG, Solomon $\mathrm{DH}$, et al. Measuring quality in arthritis care: methods for developing the Arthritis Foundation's quality indicator set. Arthritis Rheum 2004;51:193-202.

6. Gillis JZ, Panopalis P, Schmajuk G, et al. Systematic review of the literature informing the systemic lupus erythematosus indicators project: reproductive health care quality indicators. Arthritis Care Res 2011;63:17-30.

7. Quinzanos I, Davis L, Keniston A, et al. Application and feasibility of systemic lupus erythematosus reproductive health care quality indicators at a public urban rheumatology clinic. Lupus 2015;24:203-9.

8. Ferguson S, Trupin L, Yazdany J, et al. Who receives contraception counseling when starting new lupus medications? The potential roles of race, ethnicity, disease activity, and quality of communication. Lupus 2016;25:12-17.

9. Speroff T, O'Connor GT. Study designs for PDSA quality improvement research. Qual Manag Health Care 2004;13:17-32.

10. Center for Disease Control and Prevention (CDC). Contraception. 2015 http://www.cdc.gov/reproductivehealth/unintendedpregnancy/ contraception.htm (Last accessed 29 Feb 2016).

11. Banas T, Hadyla-Banas I, Pityński K, et al. Use of contraception by women treated with leflunomide due to rheumatic arthritis. J Obstet Gynaecol 2014;34:60-4.

12. Accreditation Council for Graduate Medical Education (ACGME). ACGME program requirements for graduate medical education in rheumatology (Internal Medicine). 2011 (Last accessed 10 Jul 2017).

13. Warner D, Wiedemann LA. Managing copy functionality and information integrity in the EHR. J Ahima 2012;83:47-9.

14. Terry K. Avoid EHR note 'cloning while maintaining efficiency. Med Econ 2014;91:50-2. 